\title{
NEW ADDITIONS TO THE SCORPION FAUNA OF RIYADH REGION, SAUDI
}

\section{ARABIA}

\section{Al-Asmari AK (1), Al-Saief AA (2), Abdo NM (1), Al-Moutaery KR (3)}

(1) Research Center, Armed Forces Hospital, Riyadh, Saudi Arabia; (2) Department of Medicine, Armed Forces Hospital, Riyadh, Saudi Arabia; (3) Neurosurgery Department, Armed Forces Hospital, Riyadh, Saudi Arabia.

\begin{abstract}
In this work, we present additional morphological data about the scorpion fauna of Saudi Arabia. This investigation was carried out in the central region (Riyadh) of the country and identified existing and newly discovered scorpion species for taxonomic documentation while determining the medically important ones. The survey covered the entire Riyadh region, including all major districts, and collected a total of 4,164 specimens. Morphological identification of collected animals was based on identification keys. There were two species (one with a subspecies) that belonged to the family Scorpionidae, namely Scorpio maurus kruglovi $(0.02 \%)$ and Hemiscorpius arabicus (0.05\%). The latter, currently, is part of the Hemiscorpiidae family that had been upgraded from a subfamily. Eight more species from the Buthidae family were found: Leiurus quinquestriatus (7.20\%), Androctonus crassicauda (17.24\%), Androctonus bicolor (64.60\%), Compsobuthus arabicus (3.84\%), Compsobuthus werneri (0.94\%), Buthacus yotvatensis nigroaculeatus (2.31\%), Buthacus leptochelys (3.24\%) and Orthochirus innesi (0.55\%). The major locations of collection were the outskirts of Riyadh city and the airport vicinity. The specimens were transported from all central region areas in 124 short trips.
\end{abstract}

KEY WORDS: Saudi Arabia, Riyadh, Hemiscorpius, Leiurus, Androctonus.

CONFLICTS OF INTEREST: There is no conflict.

FINANCIAL SOURCE: King Abdulaziz City for Science and Technology.

\section{CORRESPONDENCE TO:}

ABDULRAHMAN KHAZIM AL-ASMARI, PO Box: 7897(775S), Riyadh, 11159, Saudi Arabia. Phone: +996 1 4777714, ext. 25100. Fax: +996 1 4786601. Email: akasmari@medu.net.sa or abdulrahman.alasmari@gmail.com. 


\section{INTRODUCTION}

Earlier studies by several investigators such as Vachon (1) as well as recent ones including Al-Hajjaj (2) and Al-Sadoon and Al-Farraj (3) described the presence of only two scorpion species in the Riyadh region (Androctonus crassicauda and Leiurus quinquestriatus), which belong to the Buthidae family. Other buthid species like Buthacus leptochelys and Vachoniolus (Buthacus) minipectinibus have not been reported in this area of Saudi Arabia, although they are found in other regions (1). Buthidae is the largest scorpion family $(4,5)$, distributed throughout numerous regions of the globe and widespread in the Old World, especially in the tropical areas of Africa.

Detailed recent information about scorpions is available in websites of scorpiology (6-11). Much controversy has recently been accumulated on scorpion taxonomy, particularly in higher level systematics and in relation to other arthropods (12). Whereas nine families were identified during the last previous decades (13-17); at least 16 families have been found in the current decade (14, 18-22). This fact was accompanied by abolishment of several families, such as Diplocentridae, and reinstatement of others, according to Prendini and Wheeler (23), based on certain morphological factors $(5,9,24-28)$. The Hemiscorpiidae family was established, abolished and finally reinstated according to the steps taken in higher systematics of phylogeny adopted by The Scorpion Files (29) that followed Fet and Soleglad (30).

Medically important species were found in previously studied regions. However, there are other ones, considered medically unimportant, that may cause intracranial bleeding and other complications $(31,32)$. Other studies and personal contacts communicated serious inconvenient encounters between humans and other scorpion species [Compsobuthus werneri, Apistobuthus pterygocercus, Scorpio maurus kruglovi, Scorpio maurus (palmatus?)] and Hemiscorpius spp. (lepturus? arabicus?). While $H$. lepturus was found in Iran, $H$. arabicus was observed in the Al-Ha'er locality, in southern Riyadh $(1,33)$.

This work aimed to recognize new species and subspecies of scorpions and to confirm the existence of reported ones. Furthermore, our purpose was also to evaluate predominant and medically important species in the Riyadh region. 


\section{MATERIALS AND METHODS}

\section{Scorpion Hunters}

A group of professional hunters, specifically recruited for this job, collected scorpions from the wild $(34,35)$. The number of professionals was increased according to the demands of this thorough survey.

\section{Scorpions}

Twelve locations were selected around Riyadh (central region) to which regular trips were scheduled. Specimens collected from these locations were taken to the Riyadh Military Hospital (RMH) Research Center in groups (batches). This study was conducted from 2007 to 2008.

\section{Colony Maintenance (Scorpion House)}

The scorpion house was designed so that each scorpion batch was housed in larger plastic containers, which were placed in rows on shelves (34-37). Each single scorpion was kept in a separate plastic box. Small rolls of cotton, soaked in water, were supplied for each animal on a regular basis.

\section{Food Supply}

A food supply colony (mealworms) was raised to provide an adequate yield to meet the food requirements $(34,35)$. These yellow mealworms, the larval stage of the darkling beetle (Tenebrio molister), were kept in large plastic buckets and fed special food weekly $(36,37)$. Mealworms were given to scorpions every two weeks.

\section{Morphological Identification of Scorpions}

Morphological identification (scientific names) of scorpions was performed according to the taxonomic keys with a zoom stereo dissecting microscope $(1,15,34,35)$. According to recently published changes in higher scorpion phylogeny and taxonomy, the steps in higher systematics (family level) adopted by The Scorpion Files (29) that followed Fet and Soleglad (30) were employed herein, where appropriate, pending changes (if any, for future works). The project consultant taxonomist confirmed the classification of collected species $(38,39)$. 


\section{Histology of the Venom Glands}

The venom glands of each scorpion collected from the Riyadh region were morphologically analyzed. Its telson was immersed in fixatives, processed, cut and stained $(34,35)$. Stained section photos were taken with an Olympus camera mounted on a microscope and then saved by computerized software. Venom glands, which are embodied inside the scorpion telson, were extensively studied and displayed as paired oval sacs in simple or folded cell layers surrounded by contractile muscles $(24,40)$. In transverse sections, their separate ducts lead to a common aculeus.

\section{The Venom}

\section{Venom collection}

Batches of scorpion specimens, collected from the different Riyadh region localities were brought to the central Research Laboratories in short trips and identified as described in earlier published studies (34). Venom was collected, in the same manner, by electrical stimulation of the telson $(34,35)$.

\section{Venom processing and storage}

The milked venom was handled by two processes, according to other published methods (34).

\section{RESULTS}

\section{The Scorpion House}

The scorpions, after being collected from the wild, were placed in small plastic containers as single specimens. There was no intention of breeding them in captivity during the study period. Tiny scorpions delivered in captivity by pregnant mothers (from the wild) were simply abandoned.

\section{Scorpion Batches and Counts}

The total number of specimens collected from this region was 4,164 scorpions. They were collected from 12 locations (Quaseem Road, Ramah Road, Nazeem Road, Airport Road, Ben Ban, Dirab, Al-Ha'er, Al-Thumama, Janadria Road, Muzahimiya Road, Al-Kharj and Khashm Al-Aan) in the central region around Riyadh (Figure 1). 
The specimens were brought in single batches to the Central Research Laboratories, $\mathrm{RMH}$, at Riyadh in 124 short trips for identification and venom collection.

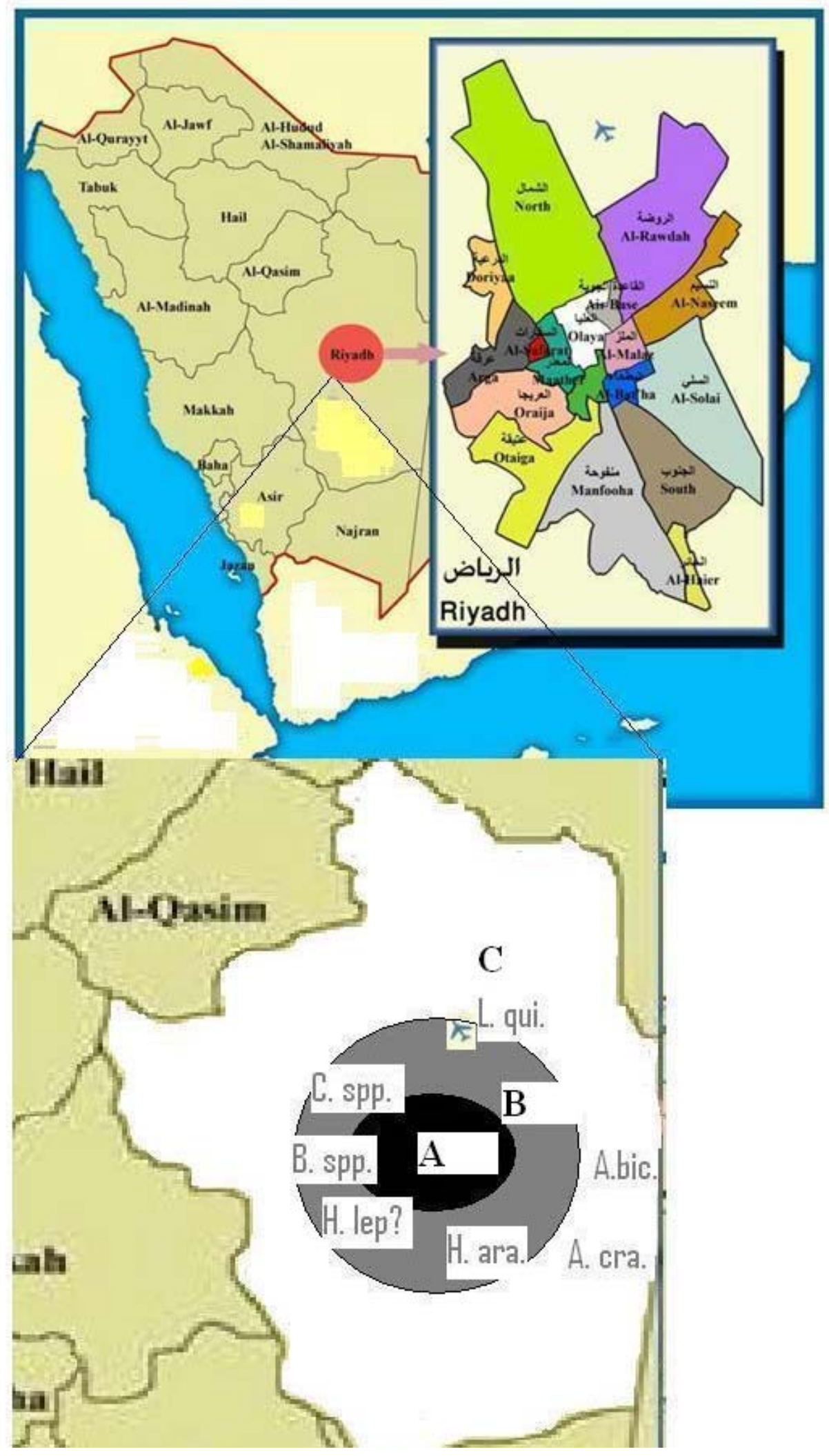

Figure 1. Map of the kingdom of Saudi Arabia, showing the distribution of scorpion species in the central region. 


\section{Morphological Examination of the Specimens}

The scorpions were identified and classified into three families (Buthidae, Hemiscorpiidae and Scorpionidae. The ten species and subspecies included seven genera (Table 1). Collection ratios, body dimensions and color of each collected species are displayed in Table 2. From the Hemiscorpiidae family, the species Hemiscorpius arabicus (0.05\%), displayed in Figure 2, was found. Of this same genus, an unknown single specimen (unsuitable for completing the study) was collected (Hemiscorpius lepturus?). The Buthidae family comprised five genera with eight species (Figures 3 to 9), namely Leiurus quinquestriatus (7.20\%), Compsobuthus arabicus (3.84\%), Compsobuthus werneri (0.94\%), Androctonus crassicauda (17.24\%), Androctonus bicolor (64.60\%), Buthacus yotvatensis nigroaculeatus (2.31\%), Buthacus leptochelys (3.24\%) and Orthochirus innesi (0.55\%). An unknown single specimen (unsuitable for inclusion in the study) that was subsequent ruled a member of the Buthidae family (genus Compsobuthus) had been collected (Compsobuthus arabicus arabicus?). The Scorpionidae family was represented in this study by one genus, a species and a subspecies (Figure 11), Scorpio maurus kruglovi (0.02\%).

The species Hemiscorpius arabicus, Leiurus quinquestriatus, Compsobuthus arabicus, Compsobuthus werneri, Buthacus yotvatensis nigroaculeatus, Buthacus leptochelys and Scorpio maurus kruglovi were yellow, with mean lengths of 6.5, 9.1, 3.1, 3.6, 7.2, 6.8 and $5.3 \mathrm{~cm}$, respectively (Table 2). The species Androctonus crassicauda, Androctonus bicolor and Orthochirus innesi were black, with respective mean lengths of $9.7,8.2$ and $2.9 \mathrm{~cm}$ (Table 2). 
Table 1. Classification of the scorpions collected from the Riyadh region

\begin{tabular}{|c|c|c|c|}
\hline Phylum & \multicolumn{3}{|l|}{ Arthropoda } \\
\hline Subphylum & \multicolumn{3}{|l|}{ Chelicerata } \\
\hline Class & \multicolumn{3}{|l|}{ Arachnida } \\
\hline Order & \multicolumn{3}{|c|}{ Scorpiones (Scorpionida) } \\
\hline \multirow[t]{18}{*}{ Family (1) } & \multicolumn{3}{|c|}{ Buthidae } \\
\hline & \multicolumn{2}{|l|}{ Genus (1) } & Leiurus \\
\hline & & Species & quinquestriatus \\
\hline & \multicolumn{2}{|l|}{ Genus (2) } & Compsobuthus \\
\hline & & Species & arabicus \\
\hline & \multicolumn{2}{|l|}{ Genus (3) } & Compsobuthus \\
\hline & & Species & werneri \\
\hline & \multicolumn{2}{|l|}{ Genus (4) } & Androctonus \\
\hline & & Species & crassicauda \\
\hline & \multicolumn{2}{|l|}{ Genus (5) } & Androctonus \\
\hline & & Species & bicolor \\
\hline & \multicolumn{2}{|l|}{ Genus (6) } & Buthacus \\
\hline & & Species & yotvatensis \\
\hline & & Subspecies & nigroaculeatus \\
\hline & \multicolumn{2}{|l|}{ Genus (7) } & Buthacus \\
\hline & & Species & leptochelys \\
\hline & \multicolumn{2}{|l|}{ Genus (8) } & Orthochirus \\
\hline & & Species & innesi \\
\hline \multirow[t]{3}{*}{ Family (2) } & \multicolumn{3}{|c|}{ Hemiscorpiidae } \\
\hline & \multicolumn{2}{|l|}{ Genus (1) } & Hemiscorpius \\
\hline & & Species & arabicus \\
\hline \multirow[t]{4}{*}{ Family (3) } & \multicolumn{3}{|c|}{ Scorpionidae } \\
\hline & \multicolumn{2}{|l|}{ Genus (1) } & Scorpio \\
\hline & & Species & maurus \\
\hline & & Subspecies & kruglovi \\
\hline
\end{tabular}


Table 2. Codes, names, colors and measurements of the identified species

\begin{tabular}{l|l|l|c|l}
\hline Code & \multicolumn{1}{|c|}{ Name } & Colour & Body (cm) & \multicolumn{1}{c}{$\%$} \\
\hline 1Riy & Hemiscorpius arabicus & Yellow & 6.5 & 0.05 \\
\hline 2Riy & Leiurus quinquestriatus & Yellow & 9.1 & 7.20 \\
\hline 3Riy & Compsobuthus arabicus & Yellow & 3.1 & 17.24 \\
\hline 4Riy & Compsobuthus werneri & Yellow & 3.6 & 64.60 \\
\hline 5Riy & Androctonus crassicauda & Black & 9.7 & 0.55 \\
\hline 6Riy & Androctonus bicolor & Black & 8.2 & 3.84 \\
\hline 7Riy & Buthacus yotvatensis nigroaculeatus & Yellow & 7.2 & 0.94 \\
\hline 8Riy & Buthacus leptochelys & Yellow & 6.8 & 2.31 \\
\hline 9Riy & Orthochirus innesi & Black & 2.9 & 3.24 \\
\hline 10Riy & Scorpio maurus kruglovi & Yellow & 5.3 & 0.02 \\
\hline & \multicolumn{1}{c}{ Total } & & 100.00 (4164) \\
\hline
\end{tabular}
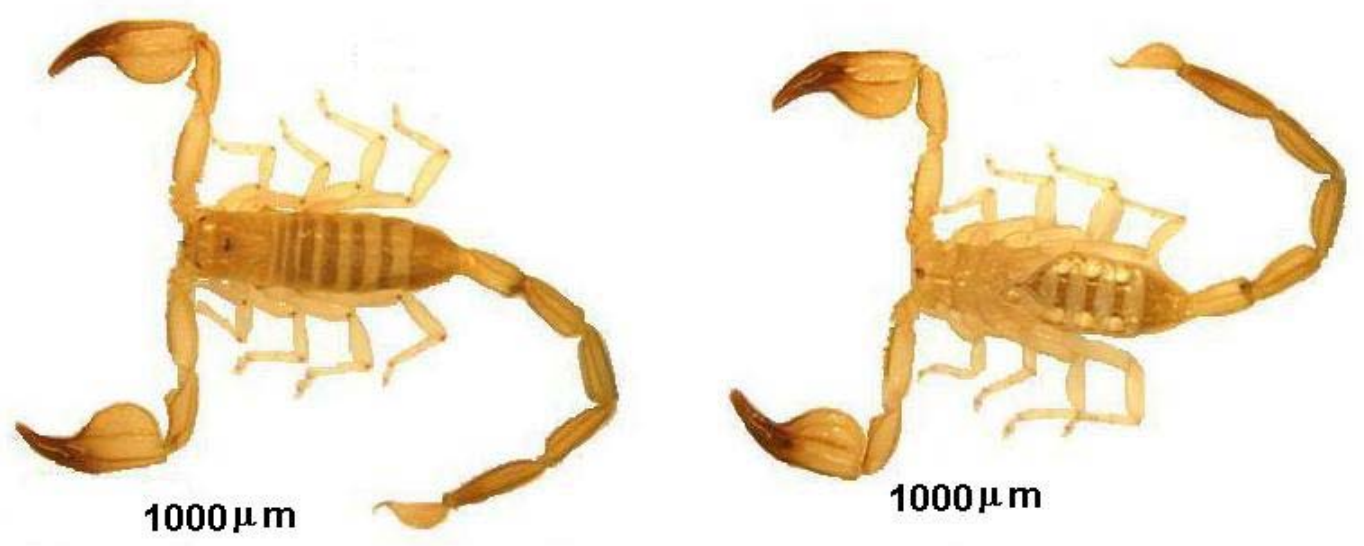

Figure 2. Hemiscorpius arabicus collected in the Riyadh region.

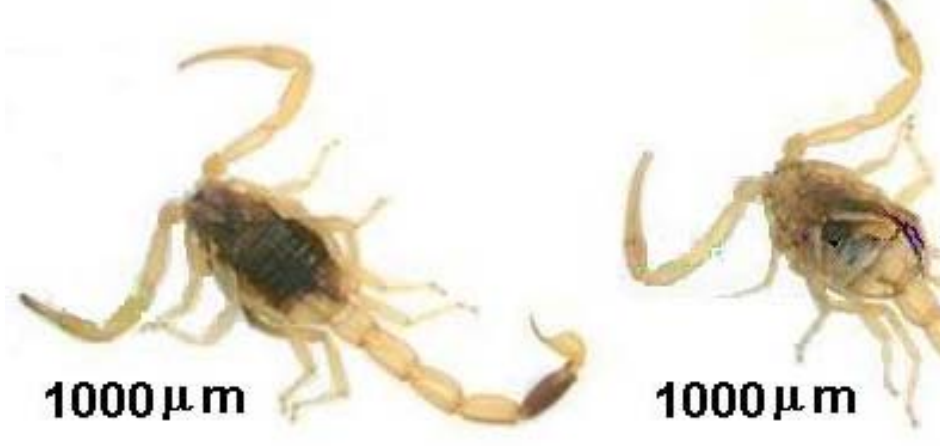

Figure 3. Leiurus quinquestriatus collected in the Riyadh region. 


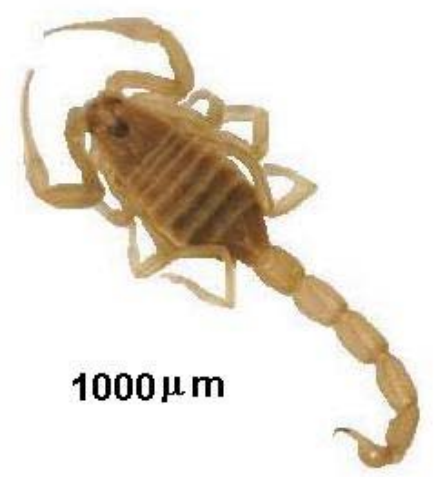

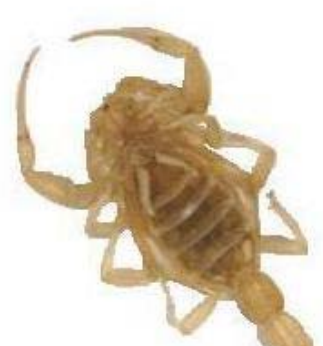

$1000 \mu \mathrm{m}$

Figure 4. Compsobuthus arabicus collected in the Riyadh region.
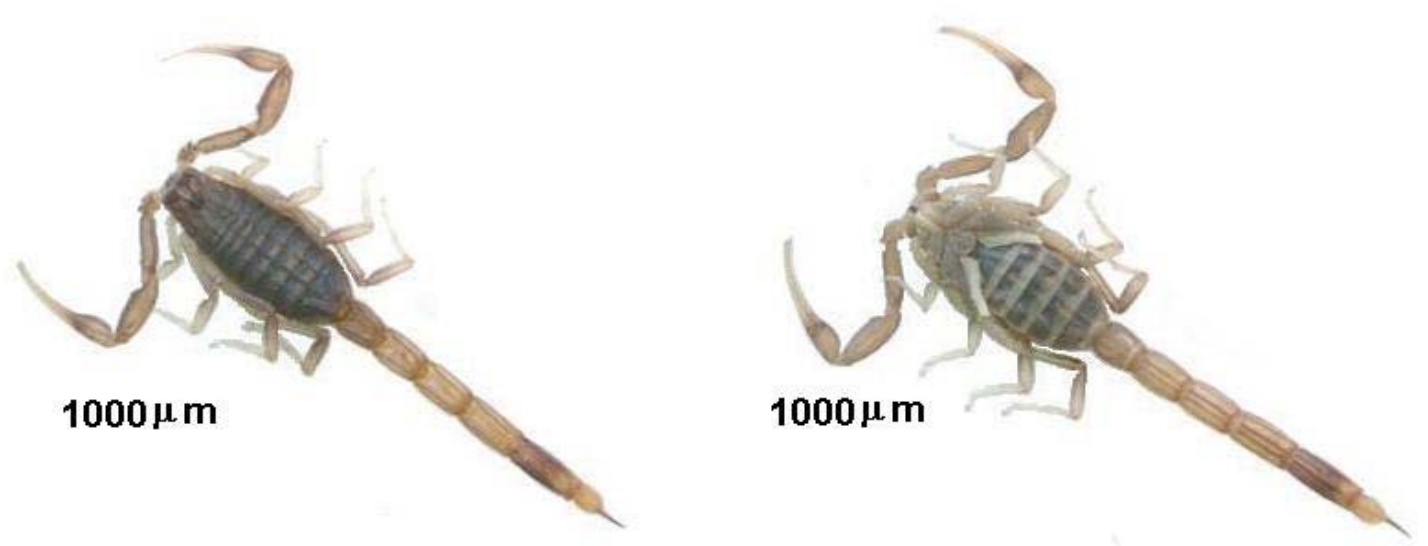

Figure 5. Compsobuthus werneri collected in the Riyadh region.
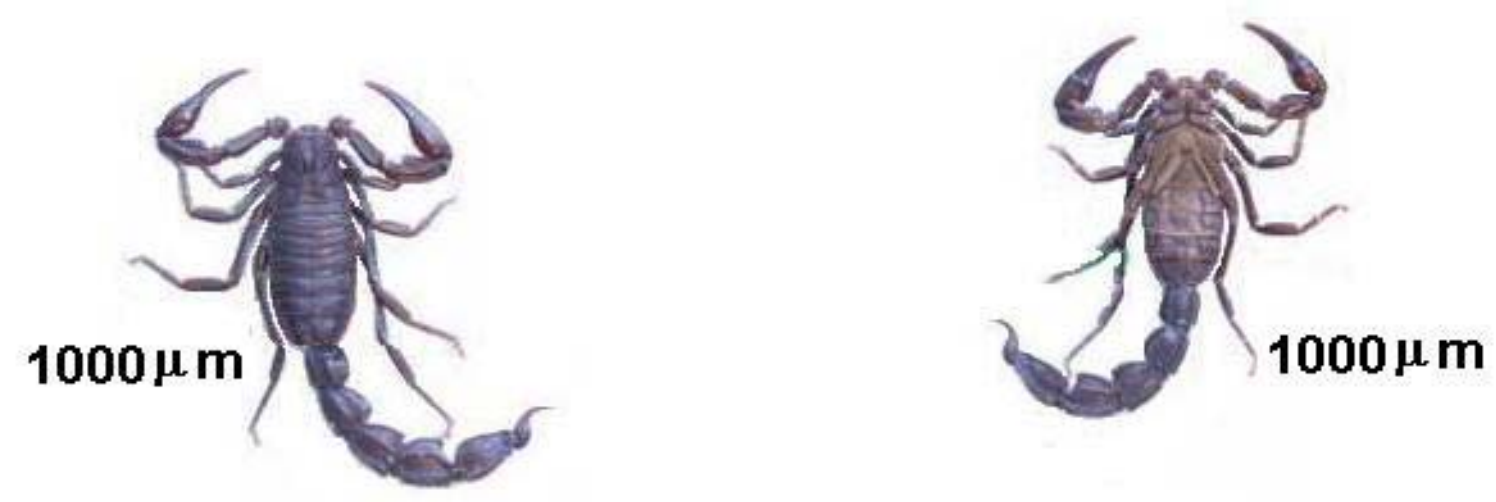

Figure 6. Androctonus crassicauda collected in the Riyadh region. 

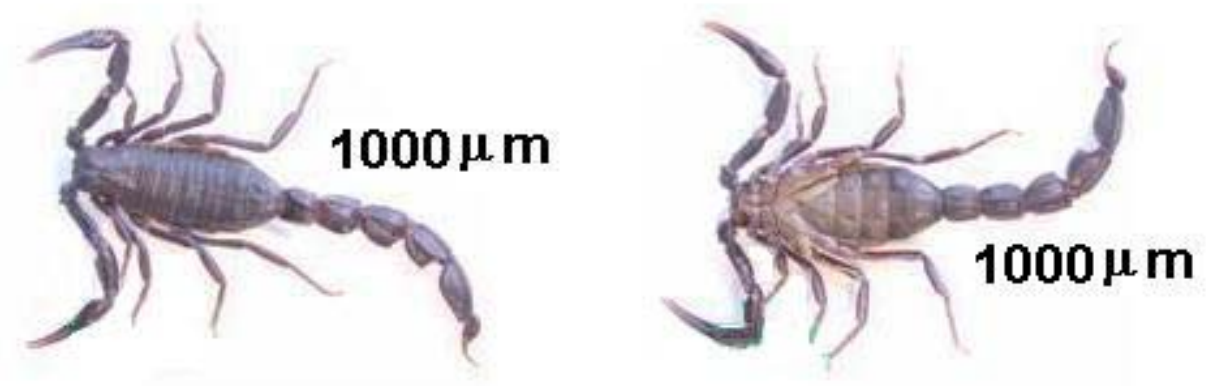

Figure 7. Androctonus bicolor collected in the Riyadh region.
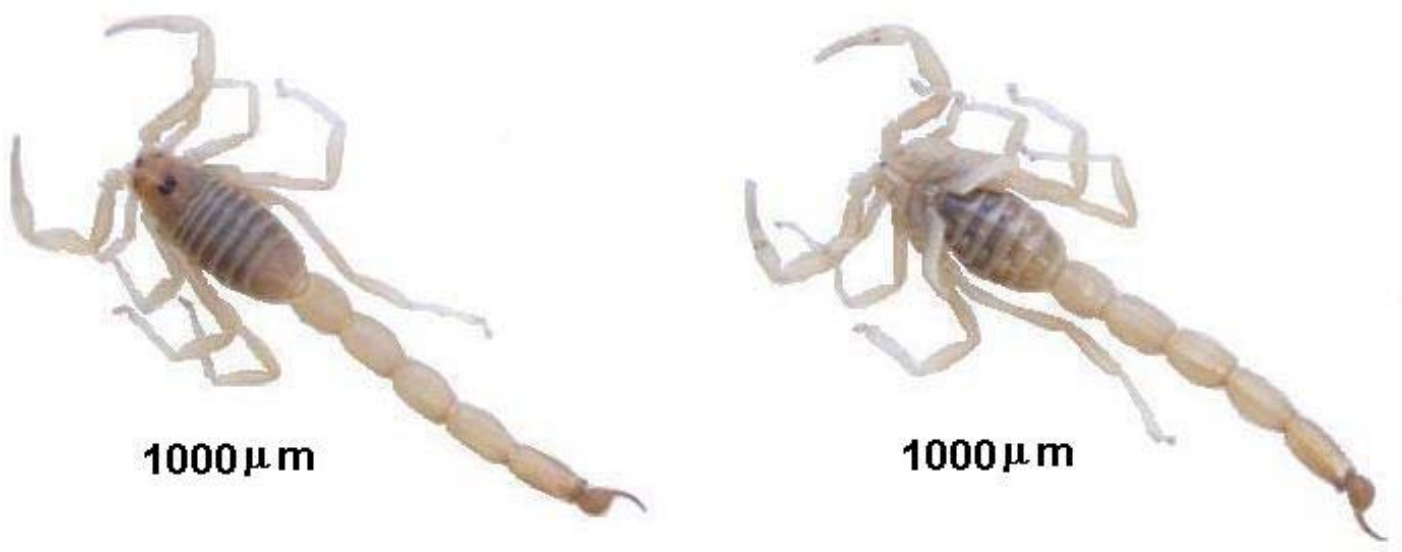

Figure 8. Buthacus yotvatensis nigroaculeatus collected in the Riyadh region.
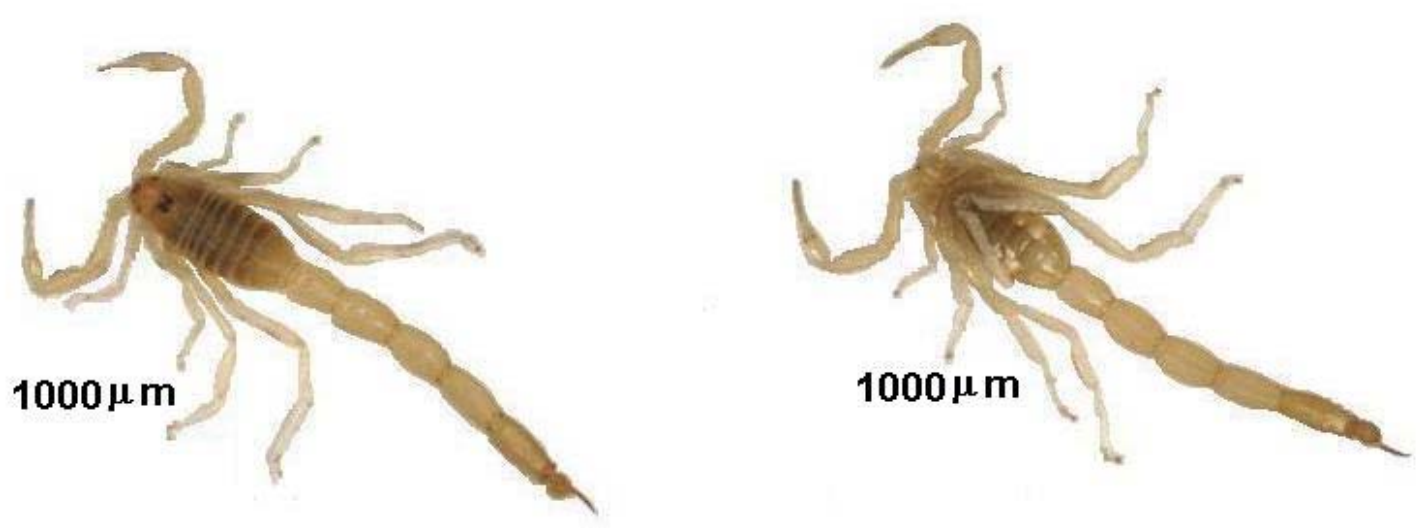

Figure 9. Buthacus leptochelys collected in the Riyadh region. 

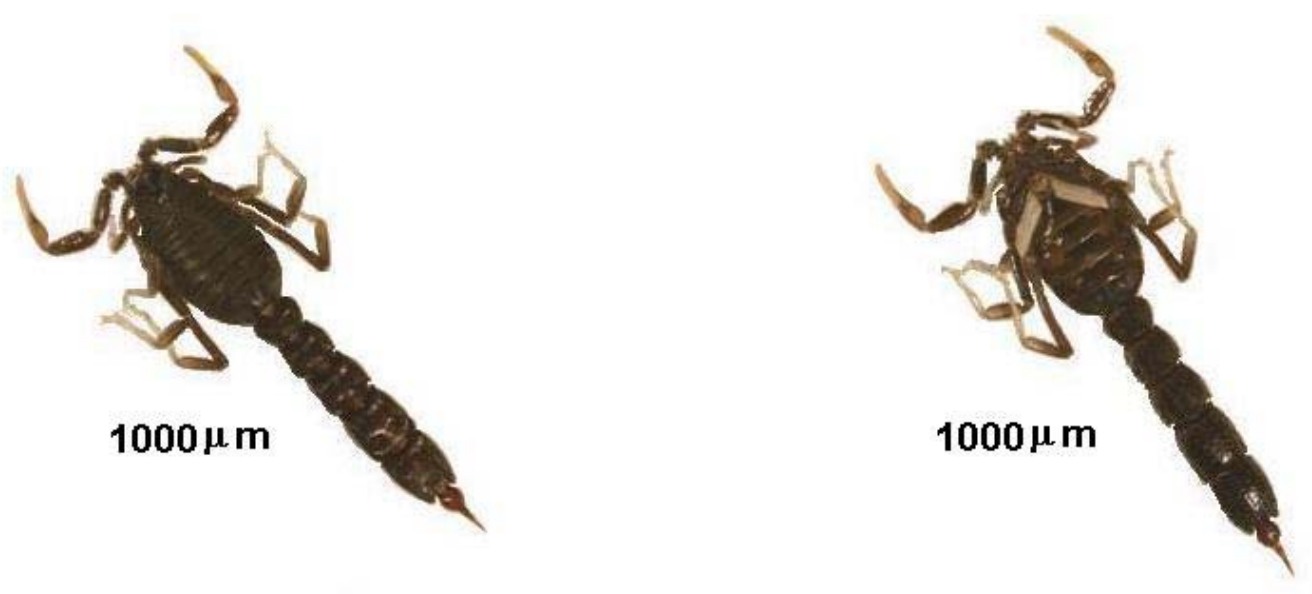

Figure 10. Orthochirus innesi collected in the Riyadh region.
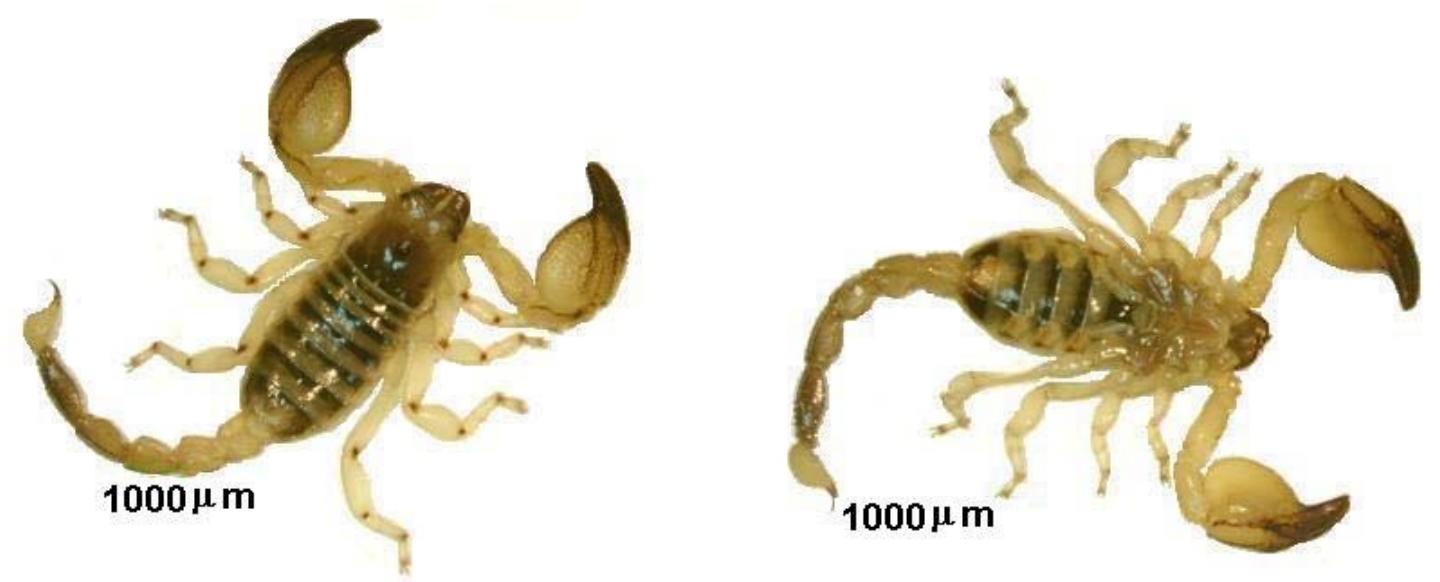

Figure 11. Scorpio maurus kruglovi collected in the Riyadh region.

\section{Histology of the Venom Glands}

Figure 12 shows histological profiles of scorpion venom glands that were collected from the Riyadh region. Telson cross sections of Compsobuthus arabicus, Compsobuthus werneri, Leiurus quinquestriatus, Androctonus crassicauda, Androctonus bicolor, Buthacus yotvatensis nigroaculeatus, Buthacus leptochelys and Orthochirus innesi reflect complex folded glands. In fact, telson sections of Leiurus quinquestriatus, Androctonus crassicauda and Androctonus bicolor present very distinct and densely folded glands. Scorpio maurus kruglovi sections, Scorpionidae family, showed simple or no folding as displayed in Figure $12-\mathrm{I}$, with one layer of a 
very thick cuticle. Hemiscorpius arabicus sections, Hemiscorpiidae family, are not shown

\section{A. Compsobuthus arabicus}

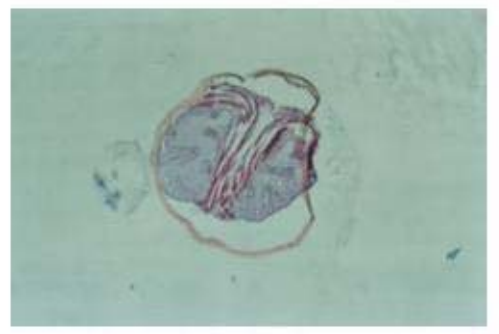

C. Leiurus quinquestriatus

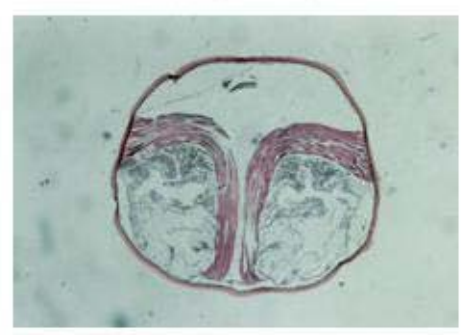

D. Androctonus crassicauda

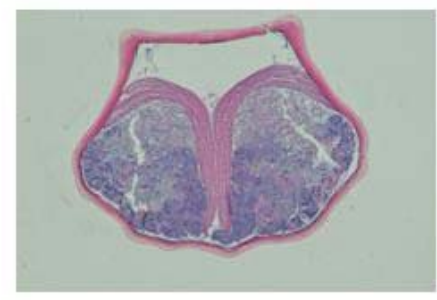

E. Androctonus bicolor

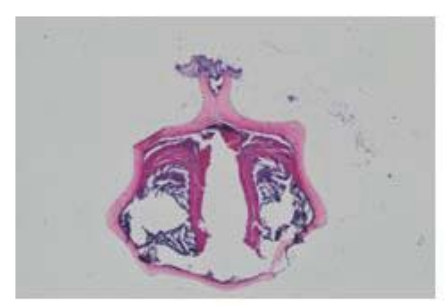

B. Compsobuthus werneri

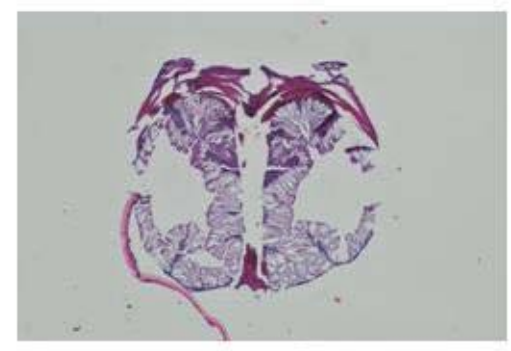

$\mathrm{C}(2)$. Leiurus quinquestriatus

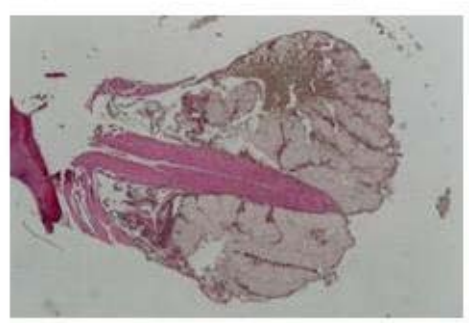

D (2). Androctonus crassicauda

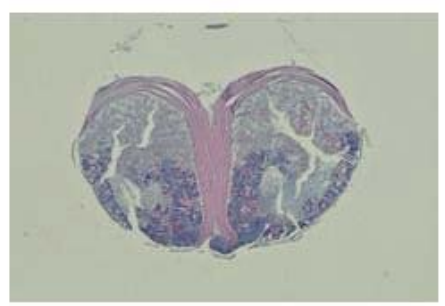

E (2). Androctonus bicolor

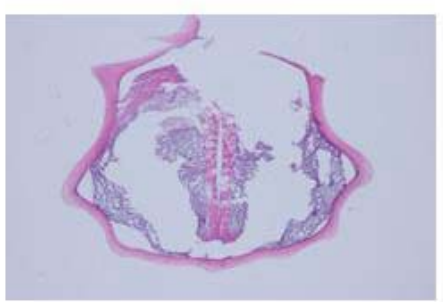




\section{F. Buthacus yotvatensis nigroaculeatus}

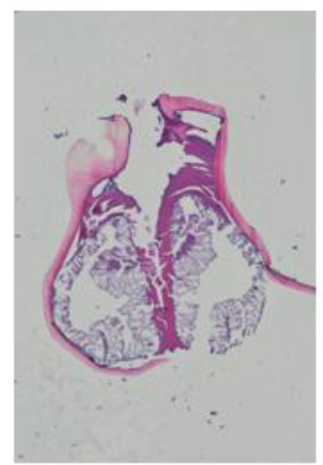

G. Buthacus leptochelys

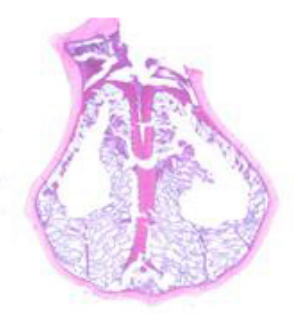

H. Orthochirus innesi

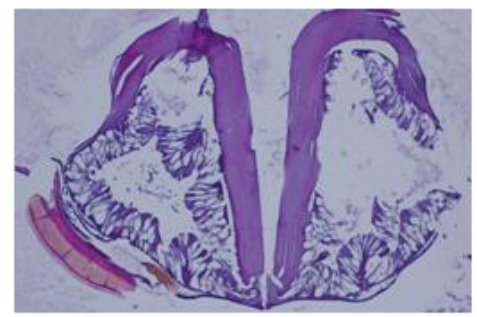

I (2). Scorpio maurus kruglovi
I. Scorpio maurus kruglovi

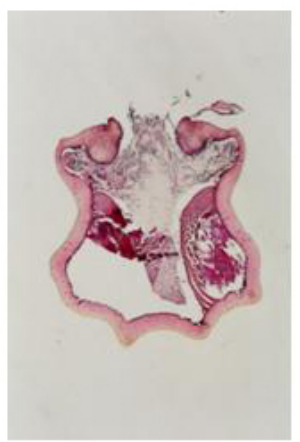

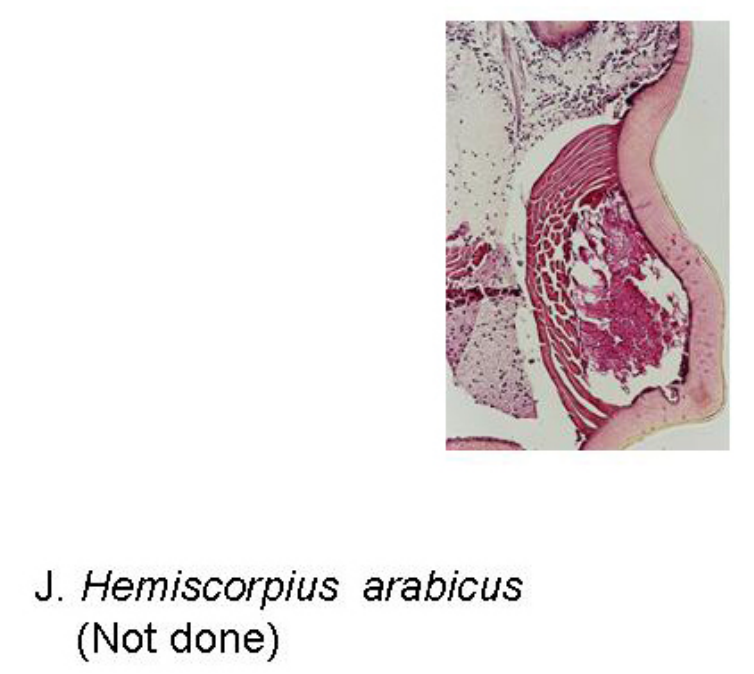

Figure 12. Cross sections of the telson of different scorpions from the Riyadh region showing the paired venom glands. Individuals of the families Buthidae, Scorpionidae and Hemiscorpiidae (not shown). (A) Compsobuthus arabicus; (B) Compsobuthus werneri; (C) Leiurus quinquestriatus; (C-2) Leiurus quinquestriatus; (D) Androctonus crassicauda; (D-2) Androctonus crassicauda; (E) Androctonus bicolor; (E-2) Androctonus bicolor; (F) Buthacus yotvatensis nigroaculeatus; (G) Buthacus leptochelys; (H) Orthochirus innesi; (I) Scorpio maurus kruglovi; (I-2) Scorpio maurus kruglovi; (J) Hemiscorpius arabicus (not done). 


\section{The Venom (Milking of Scorpions)}

Scorpion groups were milked a maximum of four times and then released in the wild. The venom was processed and stored to supply all procedures of venomology studies. The telson of dead or dying scorpions was removed, cut and dried for further processing (venom collection by telson crushing or maceration).

Venoms were collected from the following species: Leiurus quinquestriatus, Androctonus crassicauda and Androctonus bicolor.

\section{DISCUSSION}

The most recent taxonomic endeavors in higher systematics (family level) adopted by The Scorpion Files (29), that followed Fet and Soleglad (30), were applied to the identification work of Saudi Arabian scorpions. In previous works, keys described specimens collected from parts of the Arabian Peninsula, while recent updates offer more comprehensive guides $(1,2,3,38,39)$.

The present survey revealed a wide diversity of scorpion populations in the Riyadh region, with three families and a minimum of ten species and subspecies. The large amount $(4,164$ specimens) of collected animals suggests the astounding infestation degree of scorpions in these locations in the Riyadh region of Saudi Arabia. The most abundant scorpion family was Buthidae, also considered a medically important one. The three species most frequently found were Androctonus bicolor, Androctonus crassicauda and Leiurus quinquestriatus, which renders them endemic in the Riyadh region. The third species, Leiurus quinquestriatus, though it comprised the lowest percentage among these three in the Riyadh region, is notorious worldwide for its danger and is called the "deathstalker" or "lethal killer". In fact, all three species are highly venomous and, hence, considered to be of high medical importance (41-44).

Although this region is endowed with an elevated number of scorpion families (three), the species Scorpio maurus kruglovi and Hemiscorpius arabicus - representing, respectively, the families Scorpionidae and Hemiscorpiidae - are more scarce in this region (based on count percentage). They are believed to be medically unimportant; however, there is doubt about $H$. arabicus. One of the two specimens of this species had stung a patient in the Riyadh region who was then hospitalized in $\mathrm{RMH}$ with serious medical outcomes. It is worth noting that another species of the same genus and family, found not far from this area (on the eastern side of the gulf, comprising 
southern provinces of Iran), is infamous for its medical complications, namely hemolysis, renal failure, coma with extensive damage to the skin and subcutaneous tissue $(6,7,33)$. Comparative work on these two species $(H$. arabicus and $H$. lepturus) awaits further verification and correlation studies.

The coexistence of the three families in this region - Buthidae, Scorpionidae and Hemiscorpiidae - denotes that Riyadh is an endemic area for scorpion stings.

There are two species, Compsobuthus werneri and Orthochirus innesi, of the Buthidae family, that can be found in this region; however, they are considered very rare (less than one per cent of the total number). Three other buthid species are very abundant in this locality. One of them, Compsobuthus arabicus, belongs to a genus of the aforementioned scarce group. The other two, Buthacus yotvatensis nigroaculeatus and Buthacus leptochelys, are of the same genus. Although several investigators had already described the toxicity of these less common species in other regions, in Riyadh this type of study demands further clarification (4, 42, 45-50). In this region, three buthid species are black, explicitly Androctonus crassicauda, Androctonus bicolor and Orthochirus innesi. While the first two are medically important, the third, a small-sized species, is not.

Regarding colors, it is essential to note that the three more venomous scorpion groups of this region include two black species, while the remaining one, Orthochirus innesi, is yellow. This situation usually leads to confusion about the animal identification and, hence, proper medical treatment. Patients stung by scorpions generally describe their colors as yellow or black. It is also necessary to mention that it is not only coloration that leads to misunderstandings, but also the fact that some scorpion species considered weakly venomous (or medically unimportant), do present real medical significance, since they may provoke severe complications including intracranial hemorrhages and death $(6,7,9,31-33)$.

Another important point is that most of the deadly scorpions are armored with slender pedipalps and a thick tail with a prominent telson. It is understood that these species depend greatly on the powerful effect of their venoms rather than the mechanical power of their pedipalps. Lourenço (24) and Pavlovsky (40) have extensively studied scorpion venom glands. It was found that the complexity and effectiveness of the venom relies highly on the simplicity or folding of venom glands, which is related to the scorpion family and phylogeny. Furthermore, scorpions whose telson sections showed very distinct and densely folded glands (Leiurus quinquestriatus, 
Androctonus crassicauda and Androctonus bicolor) are the most toxic and medically important. The venom gland morphology presents constant generic characteristics that could be useful and applicable in higher level scorpion taxonomy.

Results of the application of modern molecular phylogenetic techniques are described in separate studies, confirming and reconfirming the identity of scorpions from this part of the Middle East and comparing them with those earlier studies (5053).

Thus, the present survey recognized the presence of three highly venomous scorpion species (Leiurus quinquestriatus, Androctonus crassicauda and Androctonus bicolor) and three families, all of which proved to have members with medical importance in this and other regions of Saudi Arabia. The elevated population of these species in the Riyadh region is quite threatening, so that detailed studies of their venoms are warranted.

In conclusion, the extensive field collections and morphological determinations of the present survey corroborated the existence of at least ten species and subspecies in Riyadh. The specific toxicity and medical importance of the species common and endemic to this region demand further attention.

\section{ACKNOWLEDGEMENTS}

The authors would like to acknowledge their deep gratitude to KACST (King Abdulaziz City for Science and Technology) for its help in sponsoring this research project. Thanks are also conveyed to Khalid Abdalla Elfaki for his technical help.

\section{REFERENCES}

1. Vachon M. Arachnids of Saudi Arabia, Scorpiones. In: Wittmer W, Buttiker W, editors. Fauna of Saudi Arabia. Basle: Ciba-Geigy; 1979. p. 30-65.

2. Al-Hajjaj A. Scorpions in the Arab world and rest of the globe. Amman: Daraldia; 2005. 120 p.

3. Al-Sadoon M, Al-Farraj S. Scorpions, in the Kingdom of Saudi Arabia. 2nd ed. Riyadh: Al-Jeraisy; 2008. 96 p.

4. Fet V, Lowe G. Family Buthidae. In: Fet V, Sissom W, Lowe G, Braunwalder M, editors. Catalog of the scorpions of the world (1758-1998). New York: The New York Entomological Society; 2000. p. 54-286. 
5. Polis GA. The biology of scorpions. 1st ed. Stanford: Stanford University Press; 1990. 587 p.

6. Arachnodata [homepage on the Internet]. Zürich: The Arachnological Information and Consulting Agency; c1986 [updated 2009 Jan; cited 2008 Jul 15]. Available from: http://www.arachnodata.ch/frameset2.htm.

7. Arachnodata [homepage on the Internet]. Zürich: The Arachnological Information and Consulting Agency; c1986 [updated 2009 Jan; cited 2008 Aug 2]. The medical and social significance of scorpionism in the southern provinces of Iran; [about one screen]. Available from: http://www.arachnodata.ch/projects.htm\#iran.

8. Euscorpius [homepage on the Internet]. Huntington: The Arachnological Information and Consulting Agency; c2001-01 [updated 2008 Jan; cited 2008 Jul 22]. Available from: http://www.science.marshall.edu/fet/euscorpius/INDEX.HTM.

9. ITG Library [homepage on the Internet]. Belgium: Illlustrated lecture notes on tropical medicine. Scorpions. 5.1. Taxonomy; c2004 Jun [updated 2009 Jan 5; cited 2009 Feb 8]. Available from: http://lib.itg.be/bibitg.htm.

10. The Scorpion Fauna [homepage on the Internet]. France: scorpions of Oman; c2003 [updated 2007 Jul 20; cited 2008 Dec 12]. Available from: http://perso.orange.fr/eycb/scorpions/AIOman.htm.

11. WRBU (Walter Reed Biosystematics Unit) [homepage on the Internet]. Suitland: scorpion identification page; c2000 [updated 2009; cited 2009 Feb 10]. Available from: http://wrbu.si.edu/scorpions/sc_phylogeny.html.

12. Fet V, Bechly G. Ischnurainae Fraser, 1957 (Insecta, Odonata): proposed conservation as the correct spelling of ISCHNURINAE to remove homonymy with ISCHNURIDAE Simon, 1879 (Arachnida, Scorpiones). Bull Zool Nomen. [serial on the Internet]. 2000 Mar [cited 2008 Dec 14]; 57(I): 26-28. Available from: http://www.science.marshall.edu/fet/euscorpius/Fet.htm.

13. Gromov A. A new family, genus and species of scorpions (Arachnida, Scorpiones) from southern Central Asia. Zool J. 1998;77:1003-8.

14. Prendini L. Phylogeny and classification of the superfamily Scorpionoidea Latreille 1802 (Chelicerata, Scorpiones): an exemplar approach. Cladistics. 2000; 16:1-78.

15. Sissom WD. Systematics, biogeography and paleontology. In: Polis GA, editor. The biology of scorpions. Stanford: Stanford University Press; 1990. p. 414-44. 
16. Stockwell SA. Revision of the phylogeny and higher classification of scorpions (Chelicerata) [doctoral dissertation]. Berkeley: University of California; 1989. 413 p.

17. Stockwell SA. Systematic observations on North American Scorpionida with a key and checklist of the families and genera. J Med Entomol. 1992;29(3):407-22.

18. Fet V, Sissom WD, Lowe G, Braunwalder M, editors. Catalog of the scorpions of the World (1758-1998) [monograph on the Internet]. New York: The New York Entomological Society; 2000 [cited 2009 Feb 8]. Available from: http://www.science.marshall.edu/fet/euscorpius/Fet.htm.

19. Prendini L. Two new species of Hadogenes (Scorpiones, Ischnuridae) from South Africa, with a redescription of Hadogenes bicolor and a discussion of the phylogenetic position of Hadogenes. J Arachnol. 2001;29(2):146-72.

20. Prendini L. A new genus and species of bothriurid scorpion from the Brandberg Massif, Namibia, with a reanalysis of bothriurid phylogeny and a discussion of the phylogenetic position of Lisposoma Lawrence. System Entomol. 2003;28(2):149-72.

21. Prendini L. Revision of the genus Lisposoma Lawrence, 1928 (Scorpiones, Bothriuridae). Insect System Evol. 2003;34:241-64.

22. Soleglad ME, Sissom WD. Phylogeny of the family Euscorpiidae Laurie, 1896: a major revision. In: Fet V, Selden PA, editors. Scorpions 2001. In Memoriam Gary A. Polis. Burnham Beeches, Bucks: British Arachnological Society, UK; 2001. p. 25-111. 23. Prendini L, Wheeler WC. Scorpion higher phylogeny and classification, taxonomic anarchy, and standards for peer review in online publishing. Cladistics. 2005;21(5):446-94.

24. Lourenço WR. Essai d'interpretation de la distribution du genere Opisthocanthus (Arachnida, Scorpiones, Ischnuridae) dan les region Neotropicale et Afrotropicale Etude taxonomique, biogeographique, evolutive et ecologique [doctoral dissertation]. Paris: L'Universite Pierre et Marie Curie; 1985. 287 p.

25. Rosin R. A new type of poison gland found in the scorpion Nebo hierichonticus (E. Sim.) (Diplocentridae, Scorpiones). Riv Parasitol. 1965;26(2):111-22.

26. Rosin R. Effects of the venom of the scorpion Nebo hierichonticus on white mice, other scorpions and paramecia. Toxicon. 1969;7(1):71-3.

27. Rosin R. Note on the alpha-hemolytic effect of the venom of the scorpion Nebo hierichonticus. Toxicon. 1969;6(3):225-6.

28. Rosin R. Paper electrophoresis of the venom of the scorpion Nebo hierichonticus (Diplocentridae). Toxicon. 1973;11(1):107-8. 
29. The Scorpion Files. [homepage on the Internet] Trondheim, Norway :Scorpion classification. [Updated 2003 Jun 20; cited 2008 Aug 14]. Available from: http://www.ub.ntnu.no/scorpion-files/.

30. Fet V, Soleglad M. Contributions to scorpion systematics. I: On recent changes in high-level taxonomy. Euscorpius. [serial on the Internet]. 2005 Mar [cited 2008 Dec 14]; 31: 1-13. Available from http://www.science.marshall.edu/fet/euscorpius /p2005 31.pdf.

31. Annobil SH. Scorpion stings in children in the Asir Province of Saudi Arabia. J Wilder Med. 1993;4(3):241-51.

32. Annobil S, Omojola M, Vijayakumar E. Intracranial haemorrhages after Nebo hierichonticus scorpion sting. Ann Tropic Paediatr. 1991;11(4):377-80.

33. Navidpour S, Kovarik F, Fet V, Soleglad ME. Scorpions of Iran (Arachnida, Scorpiones). Part I. Khoozestan Province. Euscorpius. [serial on the Internet]. 2008 [cited 2008 Dec 14]; 65: 1-41. Available from: http://www.science.marshall.edu /fet/euscorpius/p2008 67.part 2.pdf.

34. Al-Asmari AK, Al-Saif AA, Abdo NM. Morphological identification of scorpion species from Jazan and Al-Medina Al-Munawara Regions, Saudi Arabia. J Venom Anim Toxins incl Trop Dis. 2007;13(4):821-43.

35. Al-Asmari AK, Al-Saif AA, Abdo NM, Al-Moutaery KR. The scorpion fauna of AlBaha and Hail Regions, Saudi Arabia. J Biol Sci. 2009;9(2):96-108.

36. Lyon WF. Rearing mealworms. Classification of the beetle (mealworm insect). Ohioline [monograph on the Internet]. Columbus: Ohio State University; 2000 [cited on 2006 Nov 12]. Available from: http://ohioline.osu.edu/hygfact/2000/2135.html.

37. Lyon WF. Darkling beetle/Mealworm information [serial on the Internet]. Centre for Insect Science Education Outreach: University of Arizona; 1997 [cited on 2008]. Available from: http://insected.arizona.edu/mealinfo.htm.

38. Hendrixson BE. Systematic studies on the scorpiofauna of Saudi Arabia (Scorpiones: Buthidae, Diplocentridae, Hemiscorpiidae, Scorpionidae) [master's dissertation]. West Texas: A \& M University; 2002. 193 p.

39. Hendrixson BE. The Bond Lab [monograph on the Internet]. Greenville: Eastern Carolina University; 2008 [cited 2009 Feb 10]. Available from: http://core.ecu.edu/biol/bondja/hendrixson.html. 
40. Pavlovsky EN. Studies on the Organization and Development of Scorpions. Quart J Micro Sci [serial on the Internet]. 1912 [cited 2008 Feb 10]; 68: 615-43 . Available from: http://jcs.biologists.org/cgi/reprint/s2-68/272/615.pdf.

41. Dittrich K, Power AP, Smith NA. Scorpion sting syndrome: a ten years experience. Ann Saudi Med. 1995;15(2):148-55.

42. Karatas A, Colak M. Scorpions of Gaziantep Province, Turkey (Arachnida: Scorpiones). Euscorpius [serial on the Internet]. 2005 [cited 2008 Aug 02]; 30: 17. Available from: http://www.science.marshall.edu/fet/euscorpius/p2005_30.pdf.

43. Simard JM, Watt DD. Venoms and toxins. In: Polis GA, editor. The Biology of Scorpions. Stanford: Stanford University Press; 1990. p. 414-44.

44. Beaver P. Scorpions of medical importance. Am J Trop Med Hyg. 1981;30(3):745-6.

45. Karatas A. New records on the occurrence of Hottentotta saulcyi Simon 1880 (Scorpiones: Buthidae) in Turkey. Israel J Zool. 2003;49:315-6.

46. Koch LE. The taxonomy, geographic distribution and evolutionary radiation of Australo-Papuan scorpions. Published in Rec. West Aust Mus [serial on the Internet]. 1977 [cited 2008 Aug 02]; 5(2): 83-367. Available from: www.ub.ntnu.no/scorpionfiles/litterature_fulltxt.php - 23k.

47. Kovarik F. Taxonomic position of species of the genus Buthacus Birula, 1908 described by Ehrenberg and Lourenço, and description of a new species (Scorpiones: Buthidae). Euscorpius [serial on the Internet]. 2005 [cited 2008 Feb 10]; 28: 1-13. Available from: http://www.science.marshall.edu/fet/euscorpius/p2005 28.pdf.

48. Lamoral $\mathrm{BH}$. A reappraisal of the suprageneric classification of recent scorpions and their zoogeography. In: Gruber J, editor. Internationaler Arachnologen-Kongress abgehalten ander Universitat fur Bodenkultur Wien, 8, Verhandlungen, 1980. Vienna: H. Egermann; 1980. p. 439-44.

49. Levy G, Amitai P. Fauna Palaestina Arachnida. I: Scorpiones. Jerusalem: The Israel Academy of Sciences and Humanities; 1980. 130 p.

50. Fet V, Braunwalder M. The scorpions (Arachnida, Scorpiones) of the Aegean area: current problems in taxonomy and biogeography. Belgian $\mathrm{J}$ Zool [serial on the Internet]. 2000 [cited 2008 Aug 02]; 130: 17-22. Available from: http://www.naturalsciences.be/institute/associations/rbzswebsite/pdf/abstracts_130_s 1/130_s1_3.pdf. 
51 Fet V, Gantenbein B, Karatas Ay, Karatas A. An extremely low genetic divergence across the range of Euscorpius italicus (Scorpiones: Euscorpiidae). J Arachnol [serial on the Internet]. 2006 Mar [cited 2008 Dec 14]; 34(1): 248-53. Available from: http://www.science.marshall.edu/fet/euscorpius/Fet.htm PDF file.

52. Fet V, Karatas Ay, Fet EV, Karatas A. First data on the molecular phylogeny of Euscorpius (Scorpiones: Euscorpiidae) from Turkey. Zoologicheskii Zhurnal, 82 (12): 1518-1521 (Moscow, Russia) (in Russian; English summary). (English translation published in: Entomological Review) Entomol Rev. [serial on the Internet]. 2003 [cited 2008 Aug 02]; 83: 249-52. Available from: http://host.nigde.edu.tr/akaratash/ EntRev.pdf PDF file.

53. Fet V, Soleglad M, Lowe G. A new trichobothrial character for the high-level systematics of Buthoidea (Scorpiones: Buthida). Euscorpius [serial on the Internet]. 2005 [cited 2008 Feb 10]; 23: 1-40. Available from: http://www.science.marshall.edu/ fet/euscorpius/Fet.htm. 